OATACOCUE LIBRARU' MAR 9 IgU
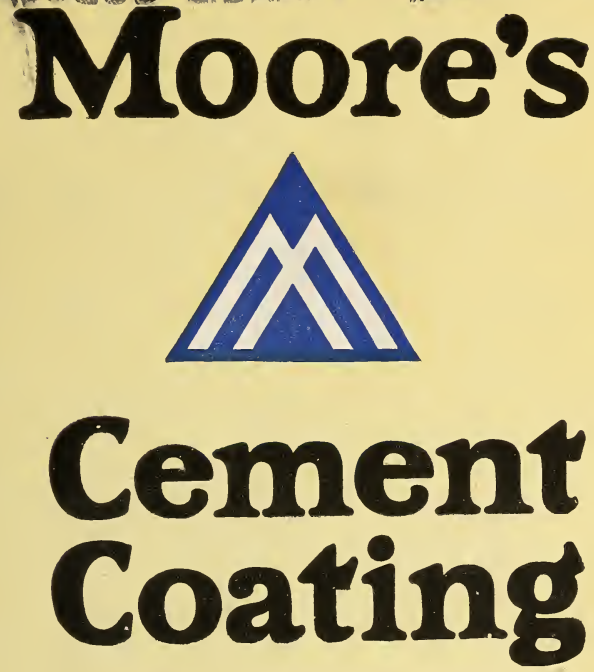

MANUEACTURED BY

BenjaminMoore\&Co.

NEW YORK CHICAGO CLEVELAND ST.LOUIS CARTERET TORONTO 


\section{Directions for Use}

The surface to be painted must be thoroughly dry, free from dirt and all loose particles of sand, lime or cement. Apply freely and evenly with a large brush, thoroughly filling all pores and cracks. Two coats should be applied. If necessary to thin, use only pure Turpentine, but never add oil, dry colors or other paints.

CEMENT COATING may be tinted by the addition of pure Oil Colors broken up in turpentine.

Shake the package well, and after opening, stir contents thoroughly.

Containers should be kept tightly covered when paint is not being used.

CEMENT COATING can be applied with either brush or spraying machine, depending upon the condition of the work to be done. All surface salts should be removed, which may be accomplished by washing with a solution of one part muriatic acid and ten parts water, after which it should be rinsed with clean water and allowed to dry. 



\section{Moore's Cement Coating}
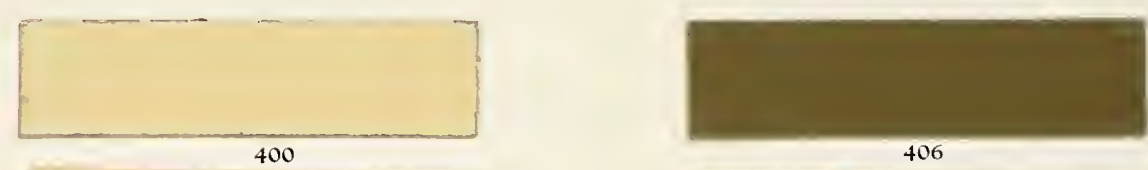

406
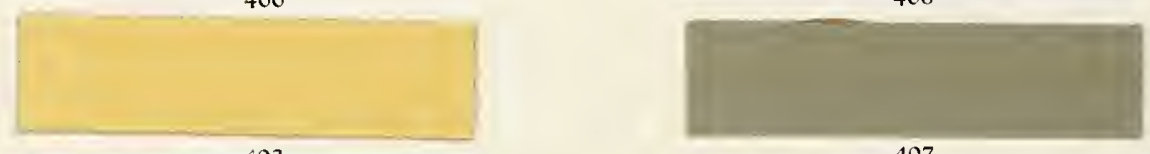

402

407
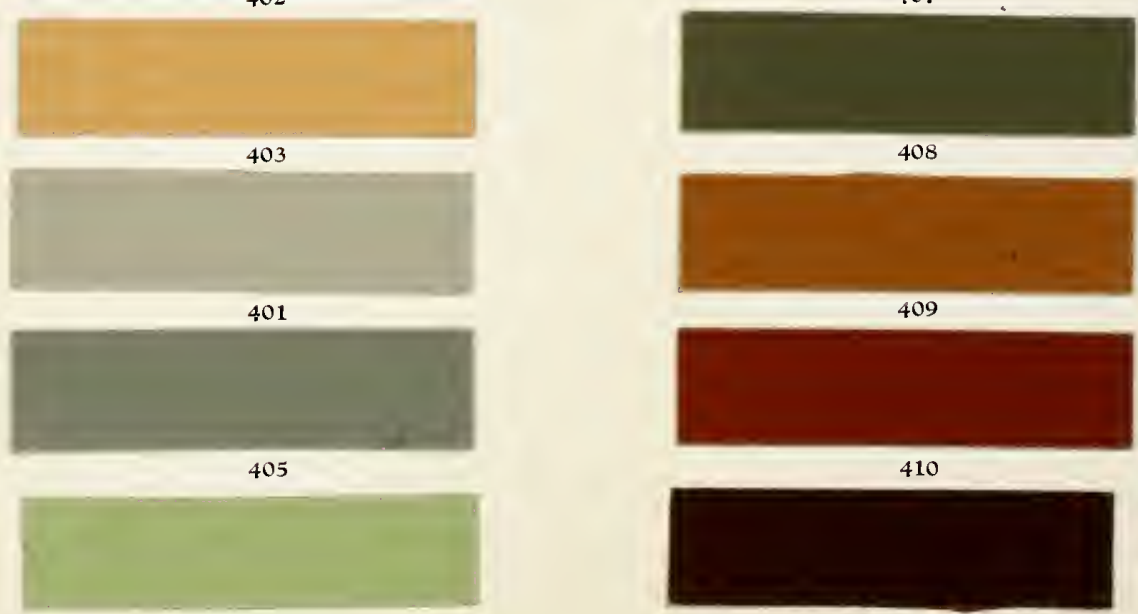

408

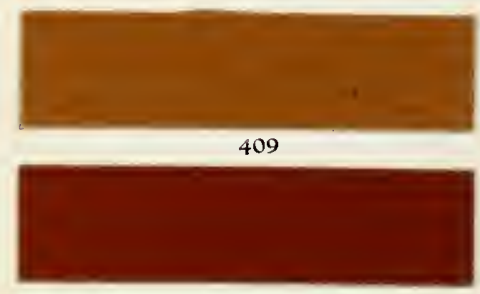

410

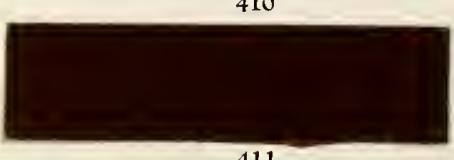

411 


\section{Moore's \\ Cement Coating}

Is the most scientific and practical preparation manufactured for the treatment and decoration of concrete, cement, stucco or plaster surfaces, both interior and exterior. When properly applied, it dries quickly and in time becomes hard, forming a part of the surface. The coating thus formed is impervious to all disintegrating influences and proof against the alkali action of cement which destroys ordinary paints.

Moore's CEMENT COATING gives an artistic appearance to the surface of cement, concrete or stucco buildings. It protects the metal or steel which may be used in their construction from corrosion and consequent destruction of the metal support. It eliminates dampness which is often the cause of the unsanitary condition of cement buildings.

Moore's Cement Coating produces a soft flat finish, and is made in White and twelve pleasing colors. 